\title{
Research on the Cultivation Method of Mechanical innovation ability for College Students in New Era
}

\author{
Hongxia Wang* \\ College of Mechanical Engineering \\ Hubei Automotive Industries Institute \\ Shiyan, China \\ e-mail:8784145@163.com
}

Huan Wang

College of Mechanical Engineering

Hubei Automotive Industries Institute

Shiyan, China

\author{
Aihua Ren \\ College of Mechanical Engineering \\ Hubei Automotive Industries Institute \\ Shiyan, China \\ e-mail: 1529263262@qq.com
}

\author{
Debin $\mathrm{Yu}$ \\ Changan Automotive Engineering Institute \\ Chongqing, China
}

\begin{abstract}
The world has entered a new era which has a higher requirement for innovation ability. The innovation ability has become an increasingly decisive key factor which determines the economic prosperity for all countries in the world. Therefore, it is necessary in order to cultivate a number of high-quality and innovative talents. For Mechanical Engineering college students, mechanical innovation is the best way to improve the competitiveness and boost their self-worth. However, the development of college students' mechanical innovation ability is still not mature. In this paper, the main problems of innovation ability training at present and some reasons for the poor mechanical innovative abilities of college students are initiatively analyzed, and some effective methods for college students' mechanical innovation ability cultivating are studied. These researches are extremely important to promote the development of college students' mechanical innovation ability enough. Finally, the methods were adopted in the experimental class. The results indicated that student's mechanical innovation ability has been improved, and the students are very happy with these cultivation methods.
\end{abstract}

Keywords-innovation; cultivation method; college student; mechanical innovation ability

\section{INTRODUCTION}

Innovation is the soul of a nation. It is inexhaustible driving force for the prosperity of a country [1]. The 21st Century is an innovation century and china has entered an era which has a higher requirement for innovation abilities. Innovation is the subject of the new era and is of paramount importance to the world's socioeconomic development. Innovation ability lies at the heart part of accomplishments and cultivating innovative talents is the priority goal of education. Cultivating and improving innovation consciousness and ability of college students meet the requirements of high-quality and innovative talents, and also respond to the call of the new era. Conventional schooling is not favorable for the cultivation of creative talents. Colleges should renew their educational ideas, which are at the core of fostering college students' thought ability and creativity.
However, the development of college students' mechanical innovation ability is still immature and the current engineering colleges involve numerous problems in the groundbreaking ability cultivation, such as the lack of innovative consciousness, weak innovation thinking ability, inadequate mechanical expertise and so on. It is a very difficult task for engineering college and the teachers especially in the recent years to cultivate mechanical inventive ability of college students. The traditional teaching mode lacks encouragement for technological innovation and scientific development. Therefore, there are many engineering colleges and some related teachers for cultivation methods of mechanical innovation ability to have carried out a wide range of research work [1-8]. Based on the previous research and according to our teaching practice in the teaching of mechanical design basic courses for many years, combining the character of mechanical engineering major, firstly, some problems of innovation ability training and reasons of the poor mechanical innovative abilities of college students are briefly analyzed, then some effective training method methods for college students' mechanical innovation ability in new era would be discussed specifically from the following aspects to improve the teaching effect. Finally, the methods were approved in the experimental class to demonstrate the validity of cultivation methods in this paper.

\section{PROBLEMS AND REAsons}

With the advent of the era of knowledge economy, the development of science and technology, almost all the countries in the world face serious challenge from international competition. Innovation ability has become an increasingly decisive key element which determines the prosperity of all nations in the world. Under this new era background, what is more, high-quality talents have the authority to realize china's leading position in the world. However, in current colleges, the mechanical innovation ability of college students continues to be insufficient. Numerous deficiencies also exist no matter in theoretical research or implementation of colleges for cultivation methods 
of mechanical innovation ability for college students, then, the influence factor of the lower mechanical innovation ability of college students would be briefly analyzed. Unfavorable factors in mechanical innovative ability's cultivation are shown in Table 1. In our experience and as evidenced in the literature, the twelve unfavorable factors in the cultivation of mechanical innovation ability are summarized. And then, the paper mainly aims to how to improve college students' mechanical innovation ability for engineering college, attempts to put forward an effective path for college students' innovation ability cultivation for the contemporary college student.

TABLE I. THE UNFAVORABLE FACTORS IN MECHANICAL INNOVATIVE ABILIT IES CULTIVATION

\begin{tabular}{|l|l|}
\hline 1 & Insufficient innovation consciousness \\
\hline 2 & Inadequate innovation ability \\
\hline 3 & Lack of persistence and willpower \\
\hline 4 & Lack of financial security \\
\hline 5 & Incompletion of incentive mechanisms \\
\hline 6 & Lack of innovative training platform \\
\hline 7 & Limited family support \\
\hline 8 & Unsatisfactory innovative environment \\
\hline 9 & $\begin{array}{l}\text { Inadequacy of effective guidance of university teachers } \\
\text { innovative quality education }\end{array}$ \\
\hline 10 & Lack of sufficient mechanical related knowledge \\
\hline 11 & Traditional educationalidea \\
\hline 12 & The traditional teacher-student relationship \\
\hline
\end{tabular}

\section{ili. Cultivation Methods}

Aim at the unfavorable factors in the cultivation of mechanical innovation ability; some methods are introduced specifically in the part.

\section{A. Strengthen ideological and political education}

To enhance the innovation ability of college students in China, there are two common obstacles: normalization of thinking and non-dynamic knowledge. The Ideological and political education, as the cultivation of college students' innovative ability of the entry point, leading them to establish a correct world outlook, outlook on life and values, it teaches students dialectical thinking, which can enhance students' ability to solve practical problems. So, it is very important to strengthen ideological and political education so as to train the ability of college student innovation, to lead students to think and to do what predecessor can't do, to improve students' quality about knowing the problem, to analyze the problem and solve the problem, to inspire college students' innovative potential, thus improving the quantity of talent cultivation to meet the requirements of national development and effectively arouse the innovative awareness and the spirit of technological innovation.

Ideological and political education makes college students understand that steady theoretical basis and strong practical ability is the foundation of innovation activities and helps to enhance students' interest in learning mechanical basic knowledge. In recent years, innovative teaching team ceaselessly renews our idea, expand our field of vision and renew our knowledge of mechanical theory in time to provide beneficial internal causes for cultivating innovative ability.
Our college often invited ideological and political experts and mechanical design experts to give academic lectures for sophomores and freshmen to make the students accept more modern ideas. What college has done also help to raise the student good moral character, cultivate strong will quality and perseverance. Thus, their thinking and analyzing capacity can be strengthened.

\section{B. System guarantee}

Cultivation of mechanical innovation ability of college students in engineering college can't be separated from the attention of the colleges and the support of funds. There is a significant role for college leaders here in making policies and measures in terms of funds, venues, equipment and supervision to provide system guarantee and incentive mechanism of technological innovation, and actively implement them. In order to stimulate the innovative awareness of college students, the college leaders have established the awarding mechanism to promote institutional innovation as well as technological innovation guarantee sustainable development to cultivate their innovative abilities and make colleges cultivate the high quality college students with the better capabilities of adapting to the developing needs of the society and the country as well.

What is more, it enables college to make the reasonable incentive mechanism for teachers to guide the students. At present, our college has improved the rewards for teachers' curriculum reform and scientific and technological innovation education, as a result, it fully mobilize the enthusiasm of teachers' participation and promote the development of university students' scientific and technological innovation activities to the depth and breadth.

Furthermore, the management systems of technological innovation activities have been established to ensure that the activities of college students can be carried out in an orderly and lasting way. The management policy of funds is made to ensure the rational use of funds. To achieve a steady improvement of college students' innovation ability cultivation, teaching reform has been deepened, the input of funds and support for scientific and technological innovation have been increased.

\section{Cultivating innovative environment}

A safe environment is conducive to the cultivation of innovation ability, while a poor environment will limit the cultivation of talents. A perfect environment which is favorable to cultivate the innovative talents includes reasonable curriculum setting, association formation, establishing innovative platform, effective guidance, teaching mode reform, science and technology competition and patent drafting, etc. Therefore, it is critical for innovational source growth to form good creative atmosphere to transform potential ability into really ability.

Aiming at the needs of cultivating the innovative talents, combining the character of mechanical engineering major, and college has set up specialized courses such as TRIZ theory, creative study theory, theory of mechanical innovation, patent drafting to create a virtuous cycle of innovation model to 
improve the college's active participation in innovation activities. People's creative thinking is systematic. Many examples of inventions reveal the mystery of imaginative thinking. It is very important for college to train their innovative ability by using the rule of creative thinking. TRIZ theory, inventive problem and solving theory, is a systematic theoretical system based on a large number of scientific knowledge and experience. It takes advantage of people's long accumulated experience and knowledge to analyze the product's whole development history to solve the various design problems at the present stage, so as to achieve product's innovative design. It provides direction for mechanical products innovative design. At the same time, the teachers are responsible for introducing a variety of new machines to expand the students' vision, introducing the writing methods and techniques of patent, encouraging students to learn thinking and write patents. A class is divided into several groups. Each group (up to 4 college students) is responsible for writing a patent. The teacher organized the whole class discussion and debate after the completion of the patent, which usually develop a perfect environment to improve critical thinking skills, and where many problems can even be solved unconsciously. Finally, some excellent patents would be chosen to declare by the teacher and the whole class, which greatly stimulated the enthusiasm of the students to write the patent.

A practical base being perspective and some association formations would be established and offered the effective guarantee academic competitions to cultivate the College's mechanical innovation ability. Based on the aim of promoting learning by competition and learning to use, our institute of mechanical engineering has set up an innovative base for college students, which provides an excellent communication platform for the college students with strong hands-on ability and innovative spirit to learn, communicate and improve. With the help of the platform, it is possible to provide personnel and technical support for the students of the mechanical engineering college to participate in the competition of various robotic competitions and innovative activities. After two years development, on the basis of the original power pioneer society, we have a successively added IE Technology Association for industrial engineering majors, ID drawing society for industrial design majors, and the Hong Chuang science and Technology Association which pays attention to practice. And every association has the exceptional teachers of various specialties. As is known to all, the high quality teachers with innovative consciousness are the most decisive factor in developing mechanical innovation ability of college students. The teachers provide a guarantee for the improvement of college student's mechanical innovation ability. Our college students have participated in various science and technology innovation competitions and won many provincial and domestic awards. They have an extraordinary spirit of innovation so far they held a number of patents for their many innovations.

Another factor that hinders the cultivation of college students' mechanical innovation ability is the traditional teaching idea. Now we are reforming the teaching mode and breaking through the obstacles of innovation ability education. Reforming of a single course evaluation method, and utilizing a variety of examination forms such as normal visits, classroom assessments, autonomy lectures, class discussion, literature searching and model making and other forms. Specific measures for teaching reform are not illustrated any further since it is already described in another article [8].

\section{Harmonious relationship}

The cultivation of students' mechanical innovation ability is inseparable from the harmonious relationship which includes teachers and students, parents and students, teachers and parents. The harmonious relationship between teachers and students is an indispensable factor for the cultivation of students' mechanical innovation ability. Without democracy, students will have to pressure when they are getting along with teachers, and look carefully at the teacher's eyes and speak, which severely stifle students' personality and passion for learning, and hinder the cultivation of students' innovative ability. On the other hand, the strong material and spiritual support of the family are the effective guarantee of the successful development of the students' innovation activities. At the same time, good communication between parents and teachers is more favorable to the cultivation of students' innovative ability. At present, students, parents and teachers can communicate effectively at any time through various information exchange platforms such as mobile QQ, microblog, We Chat and other means. More than half of the teachers in the teaching team are the class teachers. It is convenient and timely communication between teachers, parents and students when there are a few problems.

\section{TEST AND RESUlt}

To validate the effect of cultivation methods of mechanical innovation ability, the methods were approved in the experimental class. It took one year for investigating and visiting to decide whether cultivation methods can realize promotion of college student's mechanical innovation ability. Several evaluation indexes (such as number of patents, awards, examination pass rate, excellent rate and the number of participating association) were studied respectively. The test results in the regular class and experimental class are shown in TABLE II

TABLE II. TEST RESULTS

\begin{tabular}{|c|c|c|}
\hline Curriculum & \multicolumn{2}{|c|}{ Mechanical Designing } \\
\hline Class(Unit: person) & Regular class(400) & $\begin{array}{c}\text { experimental } \\
\text { class(43) }\end{array}$ \\
\hline Number of patents & $5 \%$ & $80 \%$ \\
\hline Provincial awards & $25 \%$ & $75 \%$ \\
\hline Domestic awards & $15 \%$ & $70 \%$ \\
\hline Excellent rate & $20 \%$ & $60 \%$ \\
\hline $\begin{array}{c}\text { Number of } \\
\text { participating } \\
\text { association }\end{array}$ & $30 \%$ & $90 \%$ \\
\hline Examination pass rate & $80 \%$ & $96 \%$ \\
\hline
\end{tabular}

It is observed that number of patents, number of awards and number of participating association in experimental class greatly improved. The results show that the mechanical 
innovation ability of the students in the experimental class is very strong.

\section{CONCLUSION}

The improvement of students' mechanical innovation ability is an important link in hoisting the quality of talents training in science and engineering colleges. Focused on mechanical innovation ability training of college students, according to our teaching practice in the teaching of mechanical design basic course for many years, some effective cultivation methods to improve students' innovation ability are studied. The methods were approved in the experimental class. The results show that the mechanical innovation ability of the students in the experimental class is stronger than the regular class. We conclude that these methods are effective and feasible.

\section{ACKNOWLEDGMENT}

This work was supported by the Natural Science Fund of Hubei Province (2017CFB741); the items of educational research of Hubei Automotive Industries Institute (JX201618); the Foundation of Hubei Ministry of Education (B2016089) the Doctoral Science Foundation, Hubei Automotive Industries Institute (No.Bk201406).

\section{REFERENCES}

[1] Dai Jing. Under the perspective of science and education integration of the study on agricultural college students' innovative ability training -an empirical investigation based on one of agricultural universities in wuhan[D] 2014,wuhan,huzhong agricultural university.( In Chinese)

[2] zhu xiaodong, wangjing. Research on the cultivation and evaluation of students' professional ability in career technical college [c]. Advances in social science.2017, 95:199-202.

[3] Ma xiaojun, zhangze. The training mode of mechanical talents based on professional engineering education certification [c]. Advances in social science. 2017, 95: 203-206.

[4] Rosemary Luckin. Mainstreaming innovation in educational technology [J]. Advances in Scholarship of Teaching and Learning. 2015, 3(1): 1-10.

[5] Ming Gao. Exploratory research on course teaching of architectural design based on ability cultivation of practice and innovation - Take course teaching of high-rise building design as an example[c]. SHS Web of Conferences, 2016:1-7.

[6] Fan Linan, Wu wanqiang. Discussion on the mode of cultivating innovative talents [c]. Advances in social science. 2017,95:303-306.

[7] Zhang ming. Research on the Construction of Innovation Education Curriculum System in Science and Engineering[c].Advanced in Social Science, 2016.12:44-48.

[8] Wang, hongxia Liu qiang. Research on teaching methods of autonomous learning in mechanical course[c]. Advances in social science.2017, 95:337-340. 